\title{
Allometric comparison of Georgia dairy heifers on farms and at youth shows
}

\author{
D. S. White, K. J. Duberstein, J. L. Fain Bohlen, J. K. Bertrand, A. H. Nelson, M. A. Froetschel, B. E. Davidson, \\ and W. M. Graves ${ }^{1}$ \\ Department of Animal and Dairy Sciences, University of Georgia, Athens 30602-2771
}

\begin{abstract}
Studies were conducted to determine the relationship between allometric measures of growth of Holstein dairy heifers and placing in the show ring, and to compare differences in growth between Holstein heifers that are shown and not shown. In the first study, 494 Holstein show heifers were evaluated at the 2012 and 2013 Georgia Junior National Livestock Shows. Measurements were obtained for weight, head length, withers height, hip height, thurl width, and tail length. Heifer mass index (HMI), average daily gain (ADG), and age were calculated. In total, $72.5 \%$ of Holstein show heifers were underweight. Average ADG was $0.63 \mathrm{~kg} / \mathrm{d}$, which is below the industry recommendation of 0.7 to $0.8 \mathrm{~kg} / \mathrm{d}$. Variables were ranked and converted to percentages to account for differences in class size. Withers height, head length, and HMI were most indicative of show placing. In the second study, we compared differences between growth patterns of show heifers and non-show heifers. An additional 293 non-show Holstein heifers were evaluated on 3 Georgia dairy farms during the same period as the show. In total, $43.3 \%$ of non-show heifers were underweight. Average ADG for non-show heifers was $0.71 \mathrm{~kg} / \mathrm{d}$, which is within the industry recommendation of 0.7 to $0.8 \mathrm{~kg} / \mathrm{d}$. Show heifers weighed less for their age than non-show heifers and tended to be taller at the withers than non-show heifers. The HMI scores were similar for younger show and non-show heifers, but older show heifers had lower HMI scores than non-show heifers of the same age. Show heifers had HMI scores that were lower than values calculated from standard growth data. As show heifers matured, ADG decreased, whereas as non-show heifers matured, ADG increased. Youth, leaders, and parents need to be aware of the importance of growing replacement heifers correctly so that heifers calve at 22 to 24 mo of age at an acceptable size and scale and become profitable members of the milking herd.
\end{abstract}

Received June 24, 2014.

Accepted October 9, 2014.

${ }^{1}$ Corresponding author: wgraves@uga.edu
Key words: commercial dairy heifer, allometric growth, heifer mass index, average dairy gain

\section{INTRODUCTION}

Dairy producers strive to raise their replacement heifers as efficiently as possible, minimizing costs and maximizing profitability for breeding at 14 to 15 mo of age and calving between 22 and 24 mo of age. The standards of weight and height for Holstein heifers of various ages were reported by Jones and Heinrichs (2013). Heifers must grow so that they are of adequate skeletal size and weight. This is especially important for attainment of puberty. Underfeeding heifers with lower DMI and fewer nutrients can have negative effects on puberty, calving, and lactation.

Growth is indicative of developmental maturation. Body weight and ADG are the most common indices for measuring growth. However, recent studies have explored skeletal measurements, because these are not as influenced by gut fill or body condition. Body mass index (BMI), calculated in humans as a function of weight and height, provides a practical and reliable indicator of body fat and is used in health screening (CDC, 2014). Developing similar indices for use on heifers may prove beneficial to monitor growth and development.

Since 1997, the Georgia Commercial Dairy Heifer Program has provided youth from both rural and urban backgrounds who either do not have access to dairy animals or lack resources to purchase dairy animals the opportunity to gain hands-on experience caring for and showing borrowed heifers. London et al. (2012) reported that only 82 youths entered the first year of this program, but there have been at least 300 entries since 2002. Well-grown replacement heifers must come from this program to ensure producer involvement in the future. Our studies have been driven by industry concerns for returned underweight show heifers.

The objective of the first study was to examine the relationship between weight, age, ADG, heifer mass index (HMI), head length, withers height, hip height, thurl width, tail length, and placing of commercial Holstein dairy heifers shown in the Georgia Junior Na- 
tional Livestock Show in 2012 and 2013. A new index (HMI) was developed that combined height and weight to evaluate growth. The objective of the second study was to examine the growth of Holstein non-show dairy heifers from 3 farms across the state of Georgia over the same consecutive $2 \mathrm{yr}$, using the same parameters and measurements as the first study, and compare it with growth of Holstein show heifers.

\section{MATERIALS AND METHODS}

\section{Evaluation of Commercial Dairy Show Heifers}

In the first study, 454 Holstein commercial show heifers shown at the Georgia Junior National Livestock Show were evaluated for 2 consecutive years (2012 and 2013). Heifers were born between March 1 and September 30 of the previous year (Georgia 4-H and FFA Livestock Shows Rules and Regulations, 2012-2013). Birthdates from entry information were used to calculate age (d) and ADG. Heifers exhibited at the Georgia Junior National Livestock Show each had a state ear tag with a unique number.

Data were collected at check-in at the Georgia Junior National Livestock Show in Perry. Identification number, birth date, and county of origin were previously obtained for each animal from entries. Weight for show heifers was obtained using a calibrated digital scale at the time of check-in. Head length, withers height, hip height, thurl width, and tail length were the skeletal measurements obtained on each heifer. Every measurement except thurl width was obtained using a Ketchum Deluxe Livestock Measuring Device (Ketchum Manufacturing Inc., Brookville, ON, Canada). Head length was measured as the distance from back of the poll to tip of muzzle. Withers height was measured as the distance from the point of withers to ground. Hip height was measured from top of the hip to ground. Tail length was measured from tail head to end of tail bone. Heifers with docked tails were excluded from tail length analysis. Thurl width was obtained using a custom-designed measuring device developed by The University of Georgia Instrument Shop (Athens). Thurl width measurement is defined as distance between thurl joints (London et al., 2012).

Heifer mass index was determined by dividing the weight $(\mathrm{kg})$ of the heifer by hip height $\left(\mathrm{m}^{2}\right.$; CDC, 2014). This formula is adapted from the human BMI formula with height at the hip replacing height from head to toe.

Average daily gain was determined by subtracting weight at the show from average birth weight, and then dividing by age (d) of the heifer (London et al., 2012). Average birth weight used for a Holstein calf was 42.2 kg (Tyler and Ensminger, 2006). Age (d) was calculated by subtracting birth date from the date that measurements were obtained (London et al., 2012).

Each show class was ranked in descending order for each of the traits. Rankings were converted to percentile rank by taking each rank and dividing by the total number of heifers within that class. Spearman rank correlations using SAS (SAS Institute, 2008) were estimated for show animals between the raw traits and between traits after conversion to percentile rankings. GLMSELECT stepwise selection (SAS Institute, 2008) was used to determine which traits were significant when placing was the dependent variable. The model used with GLMSELECT had placing in a class as the dependent variable, with year-class as 1 dependent variable and then the model selected traits that provided the best fit.

\section{Comparison of Holstein Show and Non-Show Heifers}

To provide a basis of comparison for growth of show heifers, the same allometric measurements were collected on 293 heifers from 3 farms in Georgia over the same 2-yr period. Non-show heifers selected for allometric evaluation had to meet the same age requirements and criteria as Holstein show heifers from the first study. Farm identification numbers were used as the identification number for each non-show Holstein heifer. Birth date was provided for each heifer by the producer. A Dairy Weight Tape (Nasco, Fort Atkinson, WI) was used to estimate weight of non-show heifers (McDaniel and Legates, 1965; Quaife, 2004; Dingwell et al., 2006). All remaining measurements were collected in the same manner for farm heifers as for commercial dairy show heifers. Spearman correlation calculations in SAS were used to correlate traits measured on the farm (SAS Institute, 2008).

Combined data from both non-show and show heifers were analyzed using the GLM procedure (SAS Institute, 2008). Each of the dependent variables weight, head length, withers height, hip height, thurl width, tail length, ADG, and HMI were analyzed by a model that contained type (non-show or show) and year as fixed class effects, the interaction between type by year, and age as a covariate. The effect of type (non-show vs. show heifers) was tested using the interaction of type by year as the error. Least squares means (LSM) were estimated for each of the type by year subclasses, and the standard errors (SE) for LSM were derived from type by year mean squares. Scatterplot graphs using Microsoft Excel (Microsoft Corp., Redmond, WA) were created for weight, head length, withers height, hip height, thurl width, tail length, HMI, and ADG. Scatterplots were created with age (mo) on the $\mathrm{x}$-axis and 
Table 1. Spearman correlation coefficients ( $P$-values in parentheses) between traits for ranked show heifers in each class ${ }^{1}$

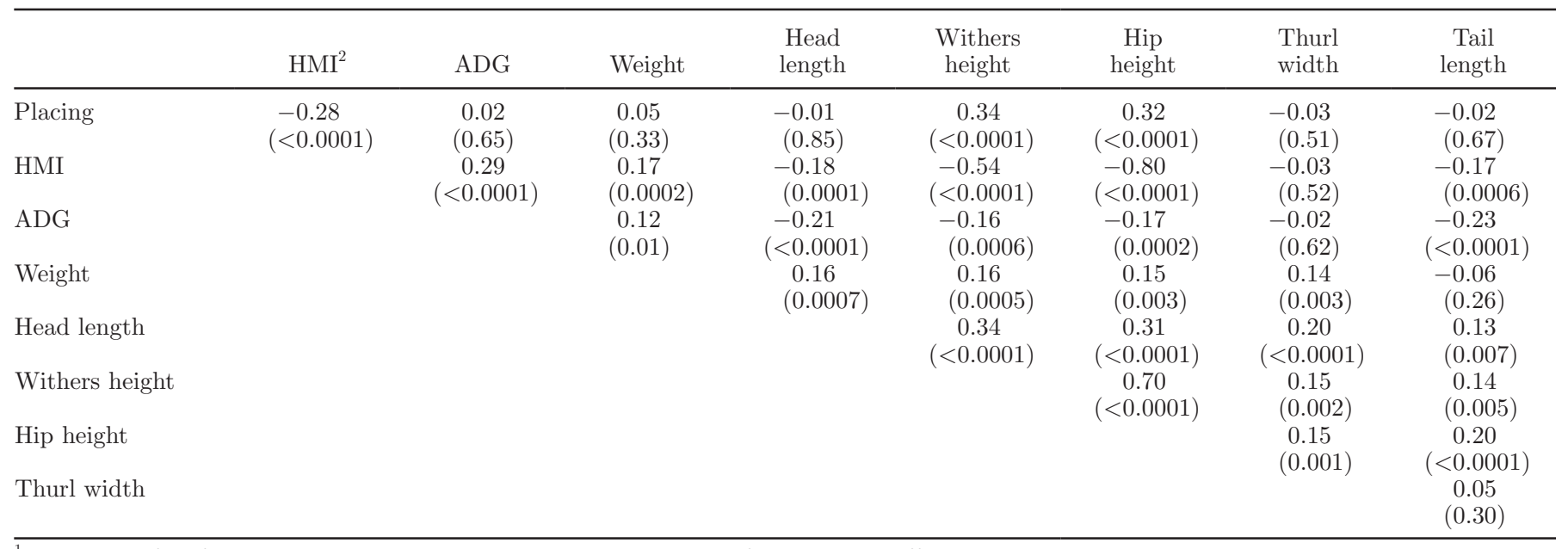

${ }^{1}$ The ranks of heifers were converted to percentile ranks to account for class size differences.

${ }^{2} \mathrm{HMI}=$ heifer mass index.

the measurement on the y-axis. These graphs were used to help better visualize differences between non-show and show heifers.

An HMI growth curve was generated using the standard numbers for height and weight listed in the Growth Monitor Spreadsheet (Pennsylvania State University, 2013). These data are based on measuring a large number of heifers of various breeds throughout the United States. Next, the Growth Monitor Spreadsheet (Pennsylvania State University, 2013) standard values were adjusted $10 \%$ to develop a second line to represent Georgia animals. West (2001) reported cows that are heat stressed deliver smaller calves, with females weighing 6 to $10 \%$ less at birth. Body weight at maturity was approximately $16 \%$ lower for heat-stressed cows. Then, the actual HMI values from show and non-show heifers from this study were plotted to compare with the standard and Georgia values.

\section{RESULTS AND DISCUSSION}

\section{Evaluation of Commercial Dairy Show Heifers}

In total, 454 Holstein show heifers at the Georgia Junior National Livestock Show in 2012 (yr 1) and 2013 (yr 2) were used in this study. Average ADG for the show heifers was $0.63 \mathrm{~kg} / \mathrm{d}$ during the $2 \mathrm{yr}$. This is below the recommended ADG of 0.7 to $0.8 \mathrm{~kg} / \mathrm{d}$ (Kertz et al., 1987; Abeni et al., 2000). London et al. (2012) found similar results $(0.65 \mathrm{~kg} / \mathrm{d})$ for commercial heifers shown from 2007 to 2010.

Table 1 shows Spearman rank correlations after the variables were converted to percentile rank to account for differences in class size. The variables that were significantly correlated with placing in a class were HMI, withers height, and hip height. Taller animals in each class tended to place higher, as indicated by correlations between hip height rank and placing (0.32) and between withers height rank and placing (0.34). Withers height rank had a moderately negative relationship with HMI rank (-0.54), and hip height rank had a very strong negative relationship $(\mathrm{r}=-0.80)$ with HMI rank; HMI rank was negatively correlated $(-0.28)$ with placing.

Heifer mass index $(P<0.01)$, head length $(P<$ $0.001)$, and withers height $(P<0.0001)$ were the traits selected for inclusion in the model to best explain differences in placing in the show ring, with $\mathrm{R}^{2}$ of $19 \%$. Table 2 presents the average percentile rank of the variables in the class relative to placing. This table shows that as heifers increased in placing from the middle $50 \%$ to the top $12.5 \%$, they also increased in height rank. However, the opposite was true for HMI, with heifers tending to decrease in HMI rank as they increased in placing from the middle $50 \%$ to the top $12.5 \%$. This further indicates that mass and body condition are lacking in those animals winning their classes. Underfeeding heifers will delay breeding, calving, and entry into the milking herd (Hopkins and Whitlow, 2013).

\section{Comparison of Show and Non-Show Heifers}

In total, 293 non-show Holstein heifers were evaluated using the Growth Monitor Spreadsheet (Pennsylvania State University, 2013) to determine the percentage of underweight heifers. The total number of heifers evaluated on each farm (and the percentage not growing to recommended levels) were 35 (31.4\%), $104(56.7 \%)$, and $154(37.0 \%)$ for farms 1 through 3, respectively. In contrast to the show heifers, where $72.5 \%$ were not 
Table 2. Average percentile rank of traits ${ }^{1}$ for classes defined by the percentile place rank of show heifers

\begin{tabular}{|c|c|c|c|c|c|c|c|c|}
\hline Placing rank class ${ }^{2}$ & $\mathrm{HMI}^{3}$ & $\mathrm{ADG}$ & Weight & $\begin{array}{l}\text { Head } \\
\text { length }\end{array}$ & $\begin{array}{l}\text { Withers } \\
\text { height }\end{array}$ & $\underset{\text { height }}{\text { Hip }}$ & $\begin{array}{l}\text { Thurl } \\
\text { width }\end{array}$ & $\begin{array}{c}\text { Tail } \\
\text { length }\end{array}$ \\
\hline$x \leq 12.5$ & 65 & 41 & 44 & 34 & 23 & 24 & 40 & 55 \\
\hline $12 . \overline{5}<x<25.0$ & 52 & 41 & 37 & 43 & 32 & 36 & 39 & 56 \\
\hline $37.5<x \leq 50.0$ & 47 & 53 & 46 & 44 & 43 & 44 & 41 & 50 \\
\hline $50.0<x \leq 62.5$ & 40 & 45 & 47 & 47 & 54 & 52 & 39 & 46 \\
\hline $62.5<x \leq 75.0$ & 42 & 43 & 45 & 44 & 51 & 49 & 43 & 61 \\
\hline
\end{tabular}

${ }^{1}$ The lower the percentile rank, the higher the heifer placed in a class when ranked solely on that trait, where taller, heavier, and so on, heifers were ranked higher.

${ }^{2}$ Where $x$ is the show placing percentile rank of a heifer within a class; for example, $12.5<x \leq 25.0$ corresponds to heifers that placed in the top $25 \%$ but not in the top $12.5 \%$ in their show class.

${ }^{3} \mathrm{HMI}=$ heifer mass index

growing adequately, only $43.3 \%$ (127 heifers) of the nonshow, farm heifers were underweight. Average ADG for non-show, farm heifers was $0.71 \mathrm{~kg}$, which is within the suggested ADG of 0.7 to $0.8 \mathrm{~kg} / \mathrm{d}$ (Kertz et al., 1987; Abeni et al., 2000).

Table 3 provides Spearman correlations for the raw traits for both show and non-show heifers. Heifer mass index was positively (and similarly) correlated with both height measures and weight in show and nonshow heifers, with animals having greater HMI being heavier and taller. This is to be expected because the mature height of the heifer is developed first (Enevoldsen and Kristensen, 1997). Interestingly, the correlation between age with weight, age with HMI, and age with height measures ranged from 0.62 to 0.76 in the show data, but had greater values in the non-show data $(0.80$ to 0.92 ). This could simply be a function of sampling; however, an implication may be that selection or management differences, or both, exist among show versus non-show heifers that alter the correlations.

The LSM estimated from the model that was fit to a combined data set containing both show and non-show data for yr 1 (2012) and yr 2 (2013) is provided in Table
4. The average ages when animals were measured for yr 1-show, yr 2-show, yr 1-non-show, and yr 2-non-show were 269, 263, 302, and $217 \mathrm{~d}$, respectively. Non-show and show heifers differed $(P<0.05)$ for withers height and thurl width, with show heifers being taller but with less thurl width than non-show heifers. Although not significantly different $(0.10<P<0.20)$, show heifers tended to have lower HMI and longer heads and were taller at the withers compared with non-show heifers.

Graphs were created to compare measurements between show heifers and non-show heifers to illustrate some possible differences between these 2 types of heifers. Show heifers were taller at the hips and withers (Figures 1 and 2). London et al. (2012) found that after evaluating frame measurements of show heifers, height at the withers had the strongest relationship with placing. Height at the withers has been reported to be the body measurement least influenced by differences in body condition (Wickersham and Schultz, 1963). A heifer should achieve $50 \%$ of her first calving height during the first $6 \mathrm{mo}$ of life (Kertz, 2013). Evidence is lacking that heifers are able to compensate later for poor initial growth during this first 6 mo. Such a study

Table 3. Spearman correlations coefficients for raw traits in show (above diagonal) and non-show (below diagonal) heifers ${ }^{1}$

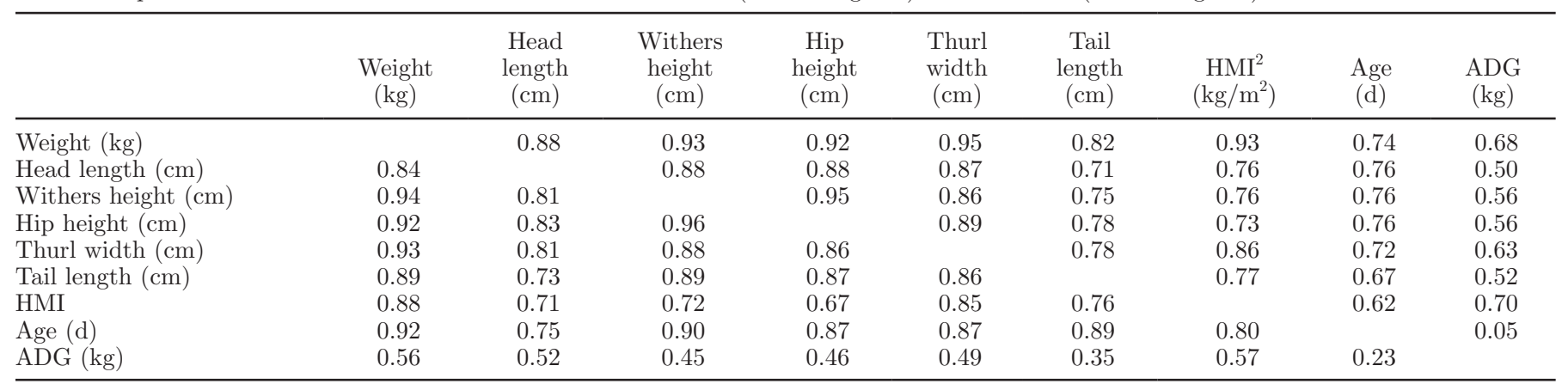

${ }^{1}$ All correlations were significantly different from zero $(P<0.0001)$ with the exception of the correlation between age with ADG $(P<0.027)$. ${ }^{2} \mathrm{HMI}=$ heifer mass index 
Table 4. Trait least squares means (SE) across years for non-show and show Holstein heifers

\begin{tabular}{|c|c|c|c|c|}
\hline \multirow[b]{2}{*}{ Trait $^{1}$} & \multicolumn{2}{|c|}{ Non-show } & \multicolumn{2}{|c|}{ Show } \\
\hline & 2012 & 2013 & 2012 & 2013 \\
\hline Weight (kg) & $226.2(10.9)$ & $233.3(10.3)$ & $214.2(8.4)$ & $202.0(8.2)$ \\
\hline Hip height $(\mathrm{cm})$ & $115.3(0.9)$ & $115.7(0.8)$ & $117.3(0.7)$ & $117.5(0.7)$ \\
\hline Withers height (cm) & $111.4(1.0)$ & $112.4(1.0)$ & $116.6(0.8)$ & $115.8(0.8)$ \\
\hline HMI $\left(\mathrm{kg} / \mathrm{m}^{2}\right)$ & $165.4(7.5)$ & $168.8(7.1)$ & $153.1(5.8)$ & $143.2(5.6)$ \\
\hline Thurl width $(\mathrm{cm})$ & $36.3(0.1)$ & $36.0(0.1)$ & $35.8(0.1)$ & $35.6(0.1)$ \\
\hline Head length $(\mathrm{cm})$ & $40.0(1.8)$ & $43.7(1.7)$ & $47.2(1.4)$ & $47.7(1.3)$ \\
\hline Tail length $(\mathrm{cm})$ & $63.5(1.1)$ & $60.3(0.8)$ & $64.1(0.9)$ & $58.0(0.9)$ \\
\hline ADG $(\mathrm{kg} / \mathrm{d})$ & $0.69(0.05)$ & $0.72(0.04)$ & $0.66(0.04)$ & $0.61(0.04)$ \\
\hline
\end{tabular}

${ }^{1} \mathrm{HMI}=$ heifer mass index.

following show heifers through their first lactation would be helpful in understanding the true effects on production.

Show heifers had longer heads than non-show heifers at a young age, but head lengths between the 2 groups became more similar with increasing age (Figure 3). Because height and longer heads were found to be important in placing, graphs show (Figures 1, 2, and 3) that heifers at each age were generally taller with longer heads, which indicates that producers select heifers for these traits specifically for shows. Heifers with a broad muzzle, large nostrils, and a strong jaw are preferred for show, and taller heifers are expected to have longer heads.

Research indicates that thurl or hip width (Figure 4) is one of the skeletal measurements more highly related to BW that is not influenced by body condition (Dingwell et al., 2006). As non-show heifers became older, thurl width was greater for their age than show heifers (Figure 4).

The graph for weight (Figure 5) indicates that show heifers weighed less than non-show heifers of the same age. Weight is given little consideration on the Purebred Dairy Cattle Association (2009) scorecard. However, both frame and dairy strength are related to weight. Figure 5 further indicates a difference in the way that show heifers are managed compared with non-show heifers. Weights between show and non-show heifers were similar at younger ages but diverged as animals aged, with differences in weight becoming more pronounced.

The HMI graph (Figure 6) shows that both show and non-show heifers had similar HMI scores when they were younger, but as they got older, show heifers had lower HMI scores than non-show heifers. This indicates that although show heifers are achieving the same or

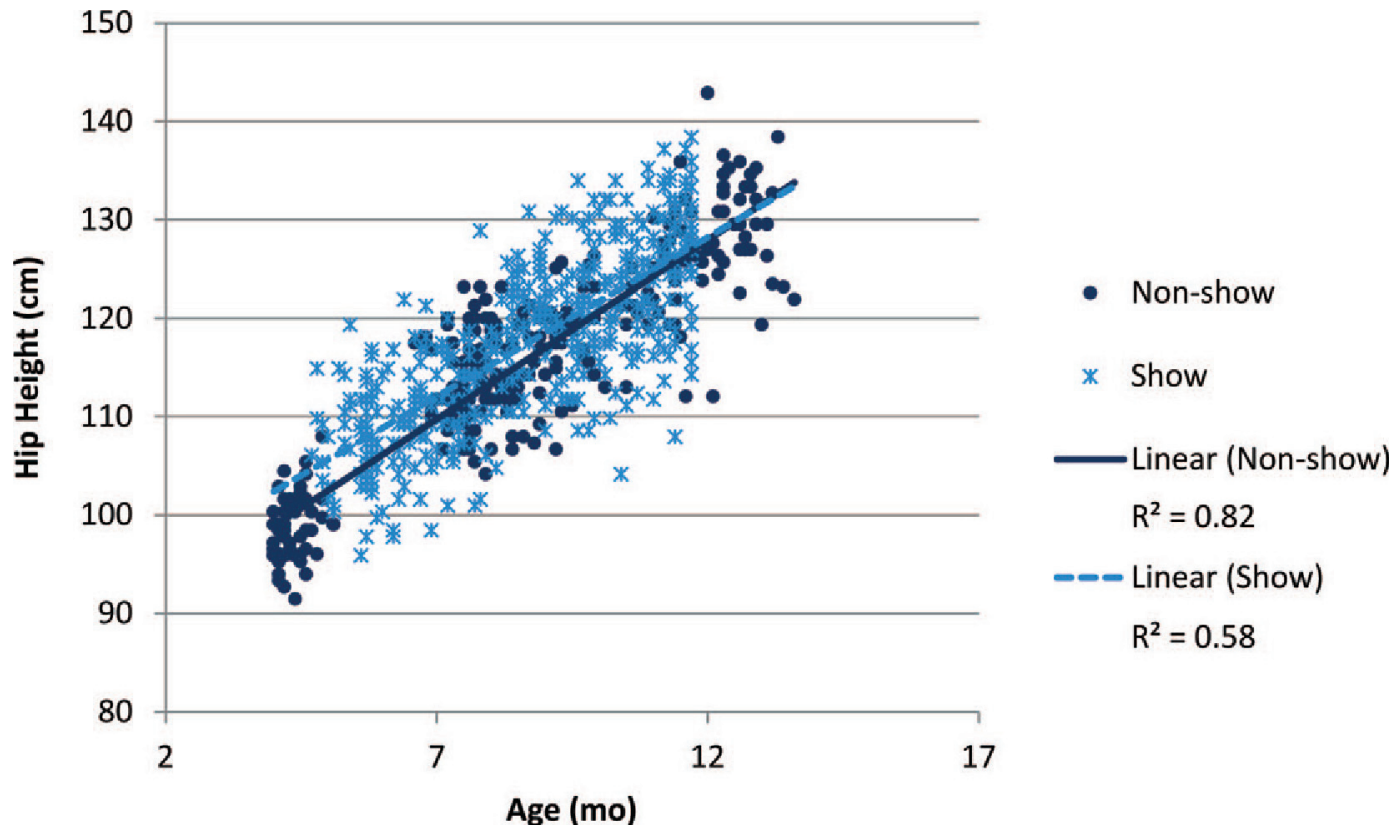

Figure 1. Comparison of hip height between show heifers and non-show heifers. Color version available online. 


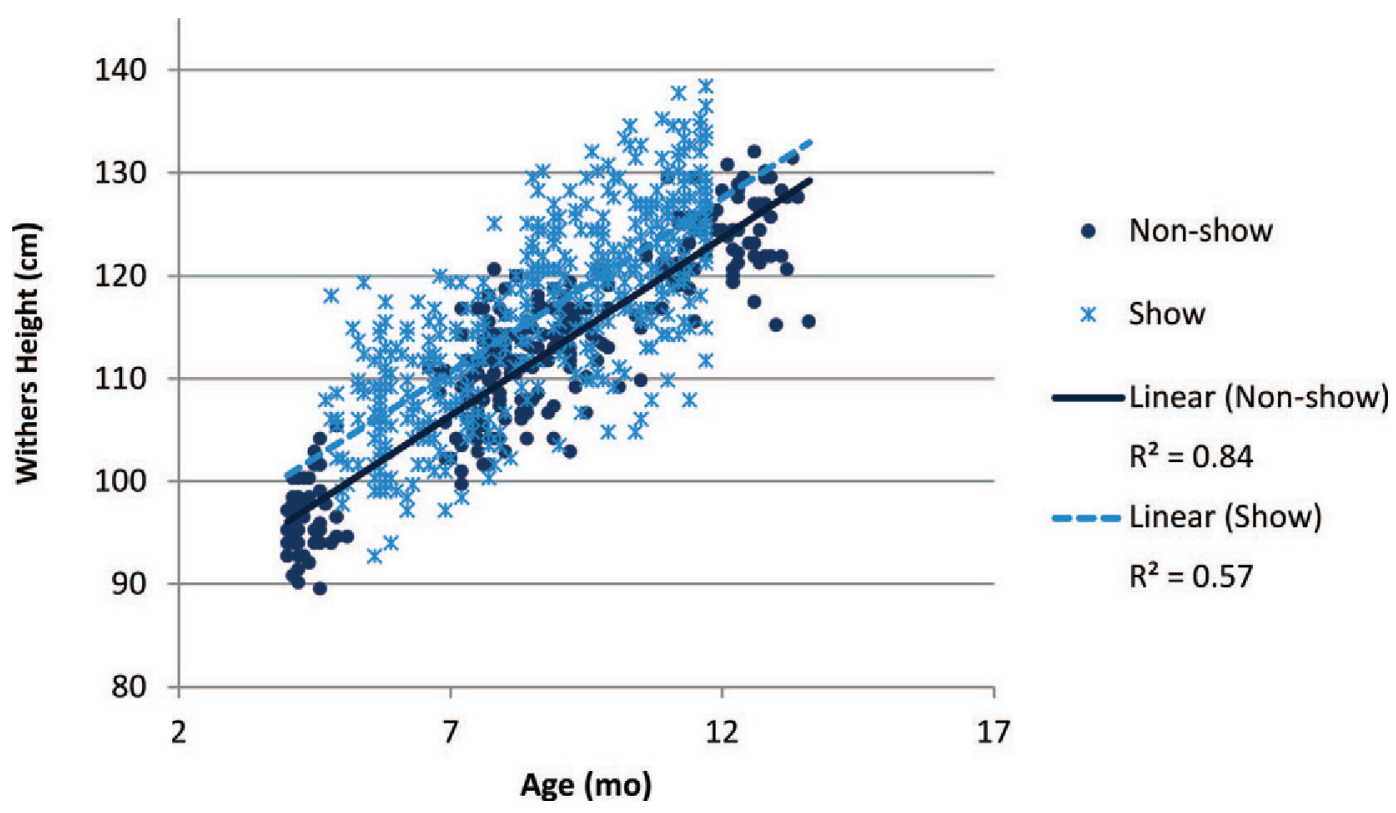

Figure 2. Comparison of withers height between show heifers and non-show heifers. Color version available online.

greater skeletal growth than non-show heifers, they do not have as much body mass as non-show heifers of the same age. Showing heifers using an index like HMI may be useful in the future because it uses 2 easily measured variables, weight and height, to develop an index to group heifers for show. Mass should play a major role in growth, especially with onset of puberty. Body depth should not be overlooked.
The graphs for HMI, thurl width, and weight (Figures 4,5 , and 6) indicate that producers did not initially select show heifers with lesser weights, less thurl width, or less HMI, but they managed show heifers in such a way to reduce weight, HMI, and thurl width compared with non-show heifers. To accentuate dairy form, show heifers are seen as having a sharper, more angular appearance.

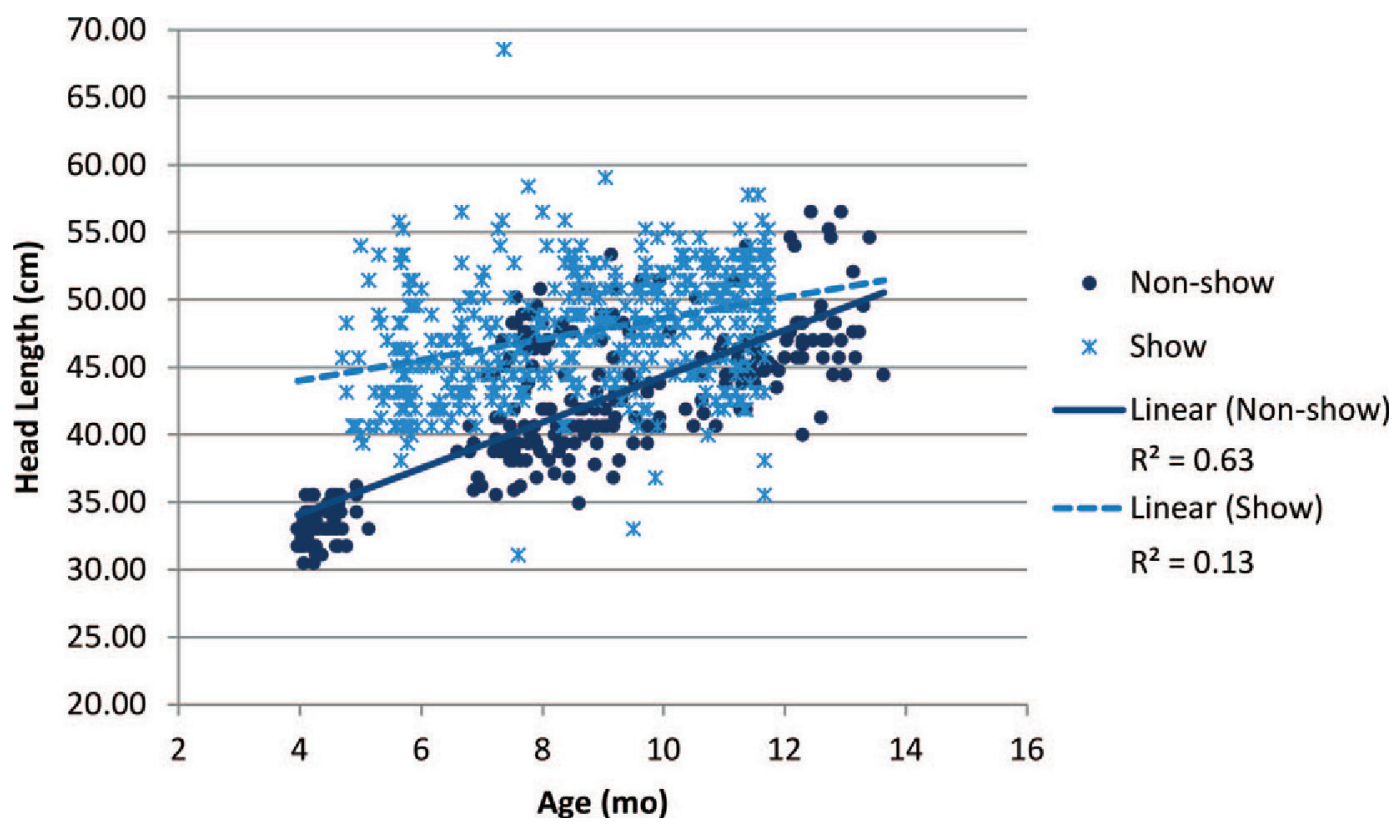

Figure 3. Comparison of head length between show heifers and non-show heifers. Color version available online. 


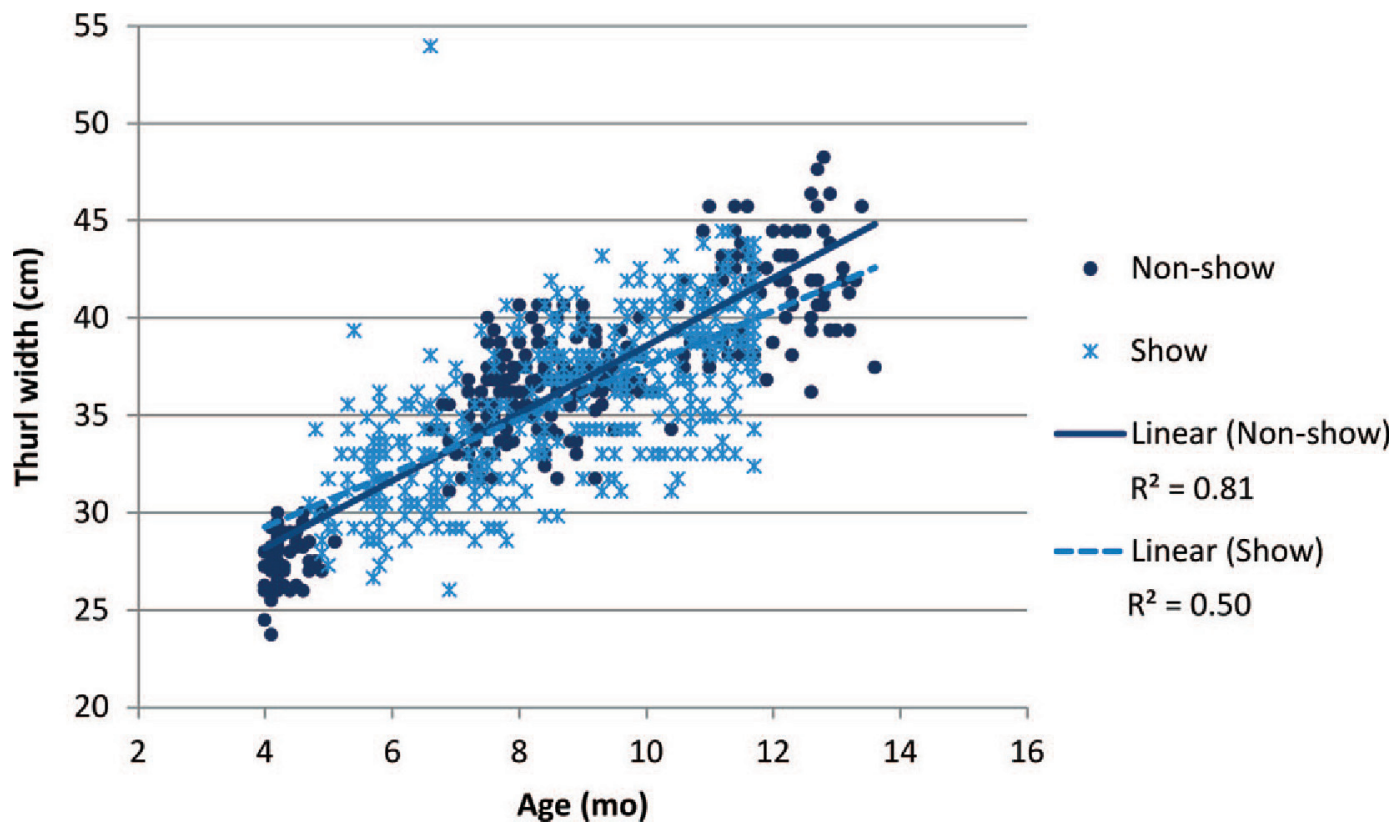

Figure 4. Comparison of thurl width between show heifers and non-show heifers. Color version available online.

The new HMI used in this study may be helpful when monitoring heifer growth. It was possible to calculate average HMI figures to plot an expected growth curve using the Growth Monitor Spreadsheet (Pennsylvania State University, 2013) standard numbers for height and weight based on measuring a large number of heifers of various breeds throughout the United States. Spreadsheet standards recommend that Holstein heifers weigh 340.2 to $362.9 \mathrm{~kg}$ and measure 121.9 to $127 \mathrm{~cm}$ at the withers at breeding and weigh 515.75 to $587.86 \mathrm{~kg}$ and measure 132.1 to $139.7 \mathrm{~cm}$ at the withers after first calving (Jones and Heinrichs, 2013). Figure 7 compares the HMI of show and non-show heifers to the optimum HMI. This provides a standard curve for HMI to compare with growing heifers. However, growing heifers in Georgia according to standard growth rates is more of a challenge because of the effects of heat stress. Heat stress has a huge economic impact on the United States

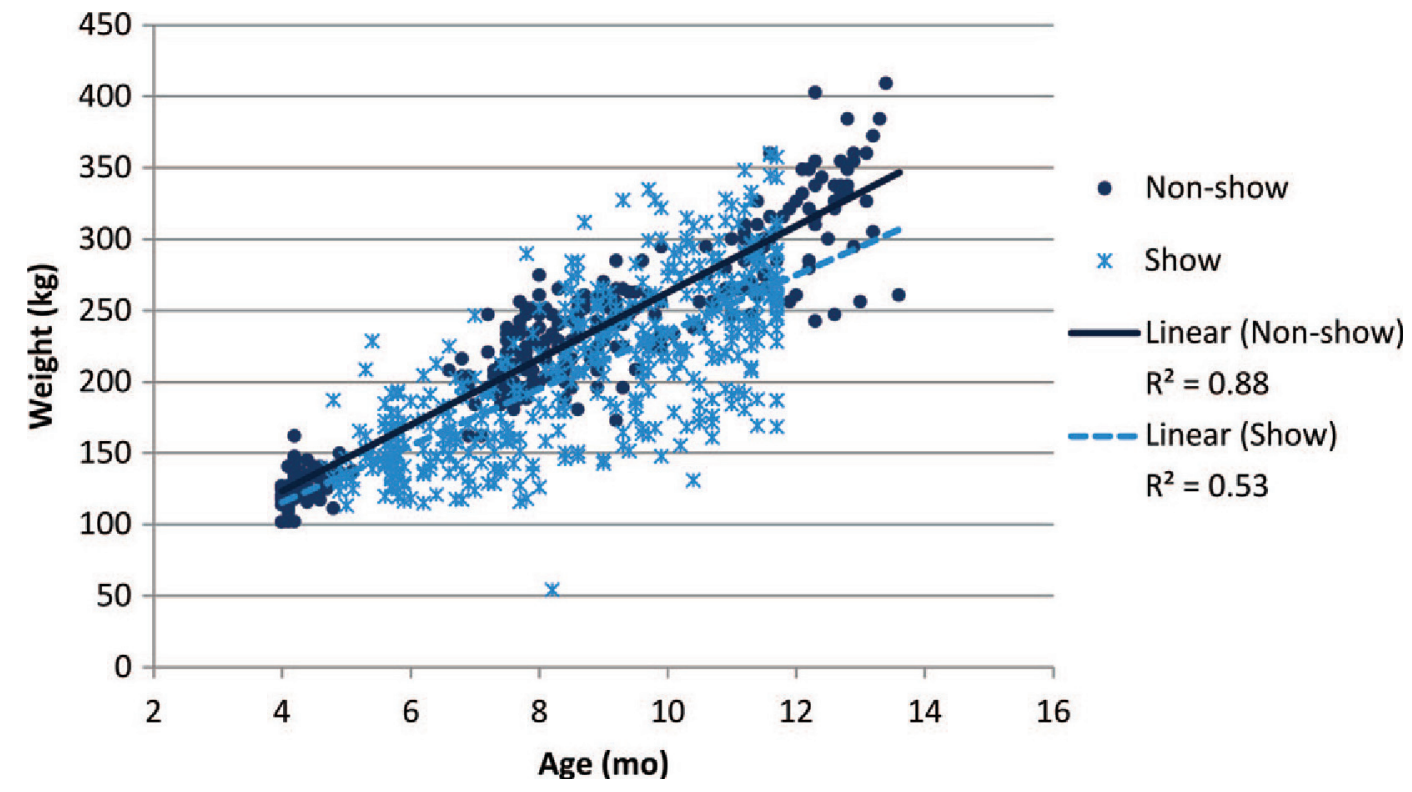

Figure 5. Comparison of weight between show heifers and non-show heifers. Color version available online. 


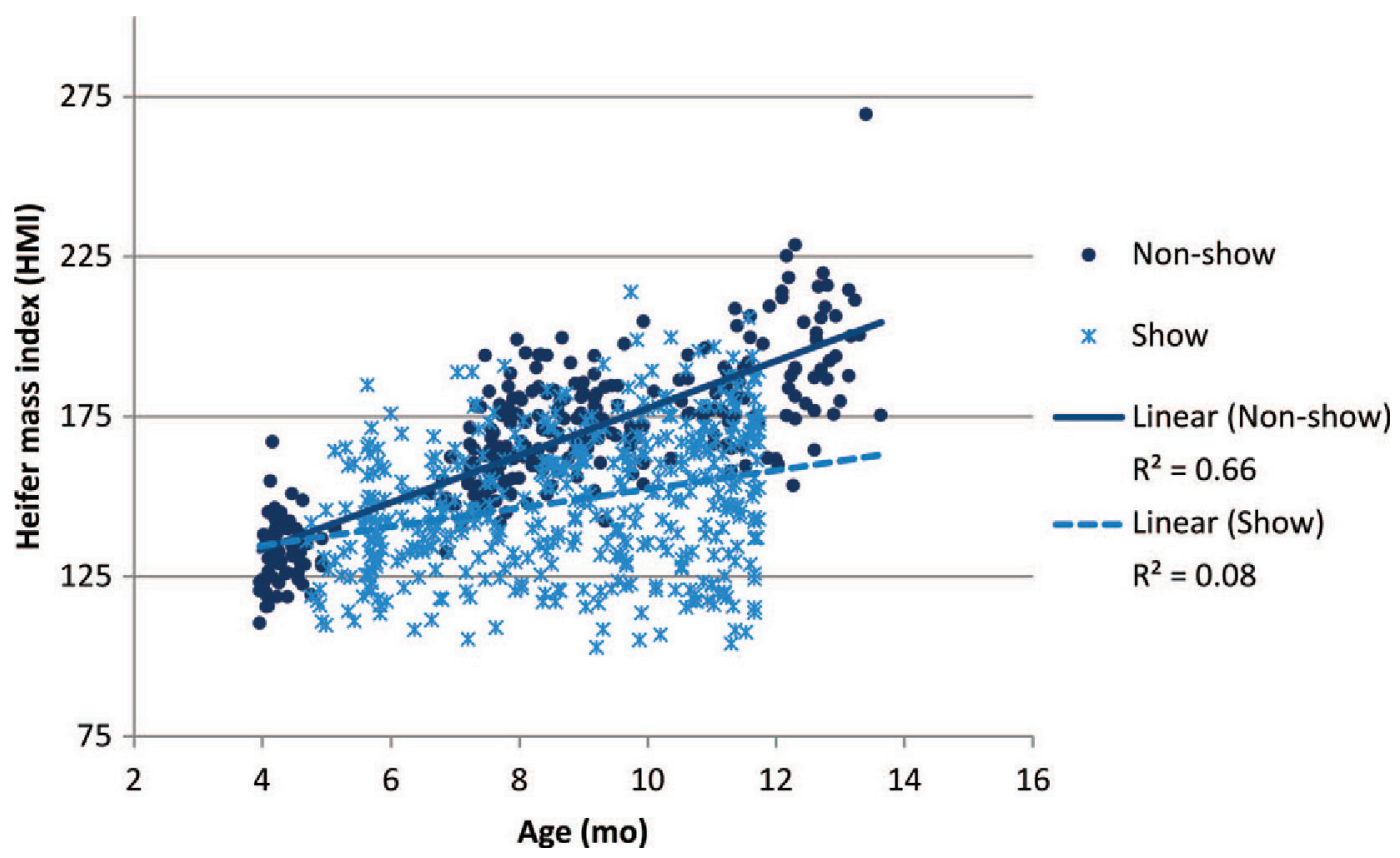

Figure 6. Comparison of heifer mass index between show heifers and non-show heifers. Color version available online.

dairy industry (West, 2001). Research shows that cows that are heat stressed deliver smaller calves, with females weighing 6 to $10 \%$ less at birth and with approximately $16 \%$ lower BW at maturity; however, cows that are shaded or have supplemental cooling during the dry period deliver larger calves (West, 2001).

Pennsylvania State standard values were adjusted $10 \%$ (an average of the 6 to $16 \%$ reported by West,

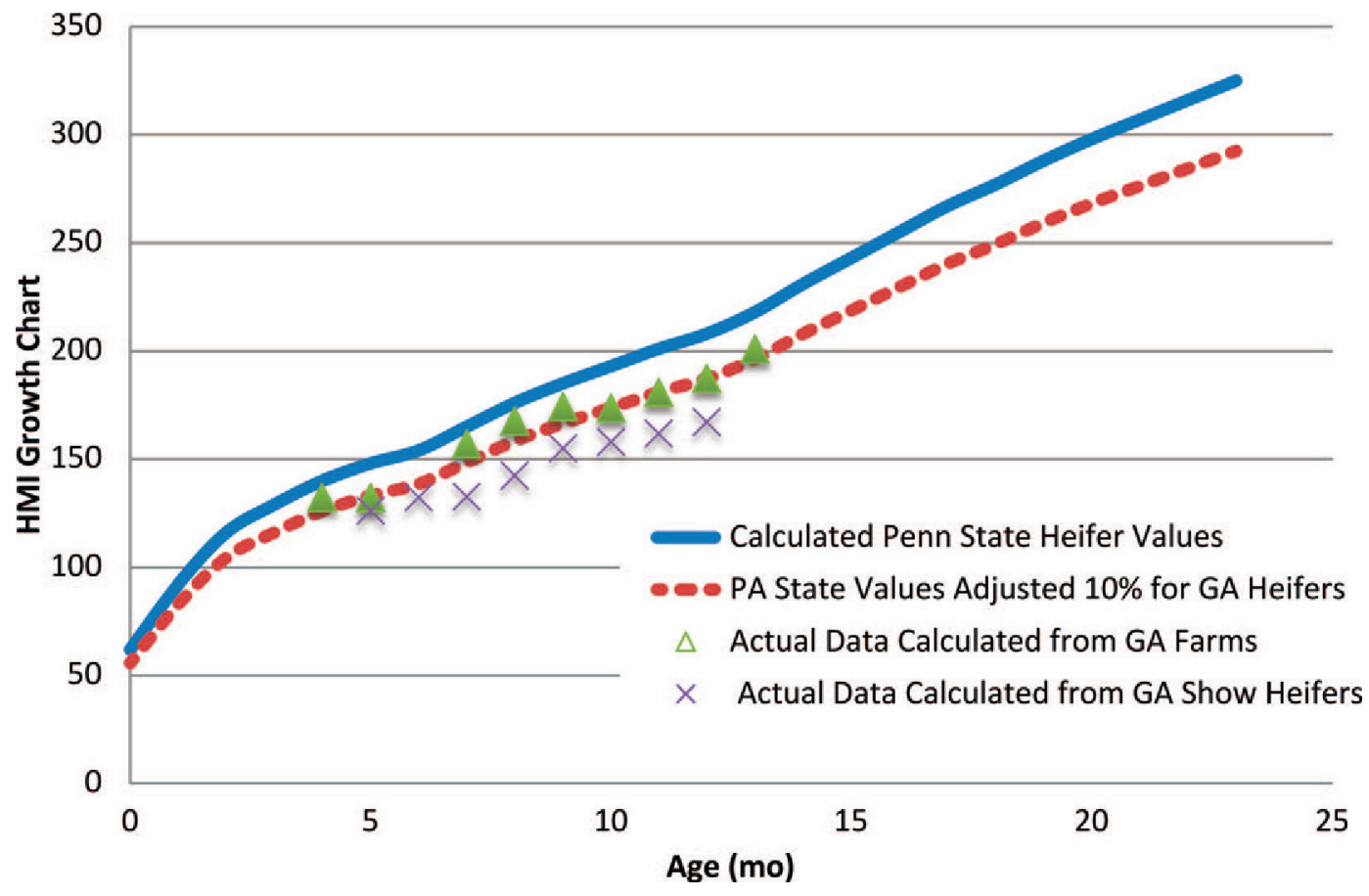

Figure 7. Comparison of heifer mass index of show heifers and non-show heifers to calculated standard values. Standard values obtained from Growth Monitor Spreadsheet (Pennsylvania State University, 2013). Color version available online. 
2001) to represent expectations for Georgia heifers, as shown in Figure 7. Non-show heifers from this study were very close to values estimated by adjusting the Growth Monitor Spreadsheet (Pennsylvania State University, 2013) to account for heat stress found in Georgia, whereas the show heifers were consistently below.

Actual HMI values for show heifers (Figure 7) indicated that they might be underfed to decrease their normal accumulation of weight compared with non-show heifers to be more competitive in the show. Underfeeding heifers can lead to stunted growth and can delay or suppress estrus. A concern seen in this study is that winning the show and developing heifers for production purposes are different goals. At the very least, show participants and those working with youth must be educated about proper development of heifers, so that heifers can return to the farm and be ready to breed at normal ages.

\section{CONCLUSIONS}

According to this study, withers height, HMI, and head length are the traits most indicative of placing. Non-show heifers are shorter and have less head length than show heifers of the same age. Show heifers appear to be managed to have a lower HMI for their age compared with their non-show heifer counterparts. Heifer mass index scores for non-show heifers are closer to the optimum than those for show heifers and are closer to values adjusted for the effects of heat stress from standard growth curve values. More research is needed to evaluate the usefulness of HMI in dairy heifer growth as well as how it relates to body mass. Heifers must be returned to the producer at the appropriate size so that they are bred to calve at 22 to 24 mo of age and become profitable members of the milking herd. Bringing awareness to youth and leaders involved in the Georgia Commercial Dairy Heifer Program on the proper growth of dairy heifers will ensure that producers continue to lend animals and support the program in the future. Smaller-framed Holsteins should be more feed efficient than larger-framed Holsteins. The ideal dairy heifer for the show ring has never been the ideal heifer for commercial milk production. A healthy commercial heifer is one that is healthy, fertile, and feed efficient, and that milks at calving. Guidelines must be developed, growth must be monitored, and standards must be enforced.

\section{REFERENCES}

Abeni, F., L. Calamari, L. Stefanini, and G. Pirlo. 2000. Effects of daily gain in pre- and post-pubertal replacement dairy heifers on body condition score, body size, metabolic profile, and future milk production. J. Dairy Sci. 83:1468-1478.

Dingwell, R. T., M. M. Wallace, C. J. McLaren, C. F. Leslie, and K. E. Leslie. 2006. An evaluation of two indirect methods of estimating body weight in Holstein calves and heifers. J. Dairy Sci. 89:3992-3998.

Enevoldsen, C., and T. Kristensen. 1997. Estimation of body weight from body size measurements and body condition scores in dairy cows. J. Dairy Sci. 80:1988-1995.

Georgia 4-H and FFA Livestock Shows Rules and Regulations. 2012-2013. The Georgia Junior Livestock Program. University of GA. Accessed Jun. 25, 2014. http://www.georgiasimmental.com/ pdf/2012/07-09-12/2012-2013_Rulebook_Corrected\%205July.pdf.

Hopkins, B. A., and L.W. Whitlow. 2013. Feeding dairy heifers from weaning to calving. NCSU ANS 01-203D. North Carolina State University Extension Bulletin, Raleigh.

Jones, C., and J. Heinrichs. 2013. Manual for Growth Monitor Excel Spreadsheet Series. The Pennsylvania State University. DAS 02-43. Accessed Sep. 2, 2014. http://extension.psu.edu/animals/dairy/ nutrition/heifers/monitoring-heifer-growth/growth-monitor-excelspreadsheets/manual-for-growth-monitor-spreadsheet-series.

Kertz, A. F. 2013. Stunt growth, stunt future performance. Hoard's Dairyman 158:493.

Kertz, A. F., L. R. Prewitt, and J. M. Ballam. 1987. Increased weight gain and effects on growth parameters. J. Dairy Sci. 70:16121622 .

London, M. L., J. K. Bernard, M. A. Froetschel, J. K. Bertrand, and W. M. Graves. 2012. The relationship between weight, age, and average daily gain to show performance of Georgia 4-H and Future Farmers of America (FFA) commercial dairy heifers. J. Dairy Sci. 95:986-996.

McDaniel, B. T., and J. E. Legates. 1965. Associations between body weight predicted from heart girth and production. J. Dairy Sci. 48:947-956

Pennsylvania State University. 2013. Pennsylvania State University Growth Monitor Spreadsheet. The Pennsylvania State University, University Park, PA. Accessed Jun. 25, 2014. http://extension.psu. edu/animals/dairy/nutrition/heifers/monitoring-heifer-growth/ growth-monitor-excel-spreadsheets.

Purebred Dairy Cattle Association. 2009. Dairy Cattle Unified Scorecard. Purebred Dairy Cattle Association, Madison, WI. Pages 1-2. Accessed Jun. 25, 2014. http://www.purebreddairycattle.com/ file_open.php?id=2.

Quaife, T. 2004. Get a handle on heifer growth. Pages 26-28 in Dairy Herd Management. Vol. 41. Vance Publishing Company, Shawnee Mission, KS

SAS Institute. 2008. SAS User's Guide: Statistics. Version 9.2 ed. SAS Inst., Cary, NC.

Tyler, H. D., and M. E. Ensminger. 2006. Dairy Cattle Science. 4th ed. Pearson Prentice Hall, Upper Saddle River, NJ.

West, J. W. 2001. New technologies in replacement heifer nutrition and management - Managing for hot weather. Pages 15-25 in Proc. Professional Diary Heifer Growers Assoc. Natl. Conf., Seattle, WA. Purebred Dairy Calf and Heifer Association, Madison, WI.

Wickersham, E. W., and L. H. Schultz. 1963. Influence of age at first breeding on growth, reproduction, and production of well-fed Holstein heifers. J. Dairy Sci. 46:544-549.

CDC. 2014. Healthy weight: Assessing your weight: Body mass index. Accessed Nov. 6, 2014. http://www.cdc.gov/healthyweight/assessing/ bmi/index.html. 